\title{
Experimental assessment of the robustness in fire of lightweight ship bulkheads
}

Hulin, Thomas; Karatzas, Vasileios; Mindykowski, Pierrick; Jomaas, Grunde; Berggreen, Christian; Lauridsen, Dan; Dragsted, Anders

Published in:

Marine Structures

Link to article, DOI:

10.1016/j.marstruc.2018.11.005

Publication date:

2019

Document Version

Peer reviewed version

Link back to DTU Orbit

Citation (APA):

Hulin, T., Karatzas, V., Mindykowski, P., Jomaas, G., Berggreen, C., Lauridsen, D., \& Dragsted, A. (2019). Experimental assessment of the robustness in fire of lightweight ship bulkheads. Marine Structures, 64, 161-173. https://doi.org/10.1016/j.marstruc.2018.11.005

\section{General rights}

Copyright and moral rights for the publications made accessible in the public portal are retained by the authors and/or other copyright owners and it is a condition of accessing publications that users recognise and abide by the legal requirements associated with these rights.

- Users may download and print one copy of any publication from the public portal for the purpose of private study or research.

- You may not further distribute the material or use it for any profit-making activity or commercial gain

- You may freely distribute the URL identifying the publication in the public portal 


\section{EXPERIMENTAL ASSESSMENT OF THE ROBUSTNESS IN FIRE OF LIGHTWEIGHT SHIP BULKHEADS}

Thomas Hulin *a, Vasileios Karatzas ${ }^{\mathrm{b}, 1}$, Pierrick Mindykowski ${ }^{\mathrm{c}, 2}$, Grunde Jomaas ${ }^{\mathrm{c}}$, Christian Berggreen ${ }^{\text {b}}$, Dan Lauridsen ${ }^{\text {a }}$, Anders Dragsted ${ }^{\text {a }}$

${ }^{a}$ Danish Institute of Fire and Security Technology, Jernholmen 12, DK-2650, Hvidovre, Denmark

b Technical University of Denmark, Department of Mechanical Engineering, Nils Koppels Allé, Building 404, DK-2800, Kgs Lyngby, Denmark

c Technical University of Denmark, Department of Civil Engineering, Brovej, Building 118, DK2800, Kgs. Lyngby, Denmark

Corresponding author: thu@dbigroup.dk

Keywords: FRP bulkheads; Lightweight bulkheads; Robustness; Fire; SOLAS vessels; Alternative design

\section{ABSTRACT}

Full-scale tests of A-60 steel and FRD-60 aluminium and FRP bulkheads exposed to fire were carried out in order to compare their respective behaviours in terms of their ultimate load-carrying capacity beyond the prescribed 60 min threshold under thermomechanical loadings. These three materials were chosen as implementation within the SOLAS framework requires documenting a level of robustness equivalent to that of steel. This is a complex process since robustness is not clearly defined and no procedure exists to quantify it. It was found that robustness can be quantified as a time-to-mechanicalfailure and is highly dependent on the fire scenario (load, fire exposure, and boundary conditions). Regulatory codes and design practices were found to disregard specific properties of alternative materials, and only consider one default scenario, which is not representative of a real-life situation. It was concluded that specific properties of alternative materials should be used and equivalence in terms of safety should be documented through performance-based design, for instance risk analyses, instead of forcing requirements originally developed for steel structures on their lightweight counterparts.

\footnotetext{
${ }^{1}$ Present address: DNV GL, Tuborg Parkvej 8, 2900 Hellerup, Denmark

${ }^{2}$ Present address: RISE Research Institute of Sweden, Box 857, SE-501 15, Borås, Sweden
} 


\section{INTRODUCTION}

The maritime industry faces growing environmental challenges as endorsed in the MARPOL convention [1] aiming at reducing pollution from ships. Research teams worldwide are investigating different solutions such as optimisation of voyage routes and fuel consumption, new propulsion systems, and introduction of lightweight materials for structural applications $[\mathbf{2 , 3}]$.

Reducing the weight of ships can lead to increased stability, decreased fuel consumption, or alternatively increase of the carried payload. In addition to environmental concerns, these solutions could therefore provide interesting economic benefits [4].

The main lightweight materials used in shipbuilding are aluminium and composites such as Fibre Reinforced Polymers (FRP) $[\mathbf{5 , 6}]$ which could lead to weight savings between 25 and $50 \%$ of the substituted elements [7]. Structures using these materials can fulfil the same performance as steel with respect to load bearing ability if challenges associated with their application have been carefully addressed [8-10].

Lightweight materials face challenges with their behaviour at elevated temperatures in such scenarios as a fire event. Aluminium will heat up and transfer heat quickly to its surroundings, and lose strength fast with increasing temperatures. FRP materials are combustible and burn if involved in fire by an external source, due to the polymer matrix binding fibres together and the sizing agents [11], thus accelerating fire spread and producing toxic smoke [12]. FRP materials also lose strength at moderately elevated temperatures due to polymer matrix degradation, displaying glass transition temperatures $\left(\mathrm{T}_{\mathrm{g}}\right)$ as low as $75^{\circ} \mathrm{C}$ for some polymers $[\mathbf{1 3 , 1 4}]$. This degradation leads to rapid stiffness loss [15-17]. Large composite panels exposed to compressive loading most commonly fail by buckling $[\mathbf{1 8 , 1 9}]$ and $\mathrm{T}_{\mathrm{g}}$ has been found to have a strong influence on buckling loads [20]. 
As a result, FRP materials are allowed and currently mostly used $[\mathbf{7 , 2 1 , 2 2 ]}$ in vessels following the International Code of Safety for High-Speed Craft (HSCC) [23] and fulfilling the requirements from the Code for Application of Fire Test Procedures (FTPC) [24]. In the HSCC, safety is based on the concept that the craft is never too far from shore, external help is available within specified time duration, and evacuation of the vessel can be completed within one third of the structural fire protection time, usually $60 \mathrm{~min}$. For SOLAS-approved ships the design must comply with the fire safety objectives and functional requirements stated in Chapter II-2 [25]. The use of FRP materials is in conflict with most of these objectives and requirements due to the aforementioned fire issues. However, Chapter II-2 Regulation 17 [25] allows using FRP materials and alternative designs, providing that fire safety objectives and functional requirements are met. This is typically achieved by proving an equivalent level of safety.

A particularly strong aspect of equivalence is documenting the same robustness in fire. This task is particularly difficult since "robustness" in its current definition is a blurry concept. Robustness can be defined as the ability of a structural element to fulfil its load bearing function when exposed to high temperatures. Thus defined, robustness becomes implicit since the existing regulatory frame requires fire resistance certification for up to a maximum of $60 \mathrm{~min}$, which is considered adequate for safe evacuation of ship occupants. Robustness is not measured beyond this timeframe. Some ships have been seen to burn for durations well beyond the FTPC requirements, sometimes for several days $[\mathbf{2 6 , 2 7 ]}$. The question whether FRP bulkheads could withstand such conditions is therefore critical to safety. As such, robustness is a qualitative concept which cannot serve as a design objective. The designer of FRP load-bearing solutions faces an arduous problem: the requirement to provide a similar performance to steel without knowing what this performance is. 
This work presents a set of fire tests performed on structural bulkheads made of steel, aluminium, and FRP materials with a perspective on robustness, i.e. when the bulkheads do not participate in the fire. The objective is to document their respective behaviour and change the engineering vision on robustness to highlight the need to make it a well-defined design parameter. This work is part of COMPASS [28], a joint research project performed by the Danish Institute of Fire Safety Technology (DBI) and the Technical University of Denmark (DTU).

\section{EXPERIMENTAL STUDY}

The tests presented herein aimed at comparing the behaviour of compression loaded ship bulkheads exposed to different fire curves as an assessment of the performance of lightweight versus standard steel designs in terms of robustness. Three different bulkhead configurations were designed and tested based on an existing passenger ferry. Two metallic configurations were designed and manufactured using steel and aluminium respectively; the third design was a FRP sandwich solution made of Glass Fibre Reinforced Polymer (GFRP) facesheets and a PET core. The experimental programme involved two large scale specimens of each configuration. Details of the test specimens are presented in Table 1. Test set-up and specimen preparation followed the requirements of the FTPC [24] Annex 1 Part 11 concerned with fire-restricting divisions (FRD) for High Speed Crafts (HSC).

\subsection{Test set-up and procedure}

Set-up

The bulkheads were placed vertically, submitted to in-plane compressive loading to reproduce service conditions, and exposed to two different fire curves. All tests were performed on the same vertical large-scale furnace, heated by 12 burners fuelled with a mix of propane and air, and controlled by the same operator. Furnace temperature was monitored by 15 standard plate thermometers uniformly 
distributed over the furnace opening and placed $100 \mathrm{~mm}$ from the exposed surface of the test specimen. Pressure in the furnace was equal to the pressure in the laboratory, at a point located 1100 mm above notional floor level, in accordance with IMO Resolution MSC.307(88) [29]. Test specimens were mounted in a reinforced concrete frame, with roll support at the top and clamped support at the bottom.

The tests aimed at investigating mechanical performance, insulation ability, and integrity. The failure criteria were as follows, based on the FTPC:

- Loss of load-bearing capacity (Mechanical performance);

- Temperature rise of $140^{\circ} \mathrm{C}$ on the unexposed surface of the bulkhead (Insulation);

- Sustained flaming of the element (Integrity).

Since the classification target was FRD60, all three criteria must be met after $60 \mathrm{~min}$ of exposure to the standard ISO 834 fire curve [30]. Special focus was placed on documenting differences in robustness between the different specimens, i.e. beyond the prescribed 60 min of classification time.

\section{Fire curves}

Two time-temperature curves were used in the tests. The standard cellulosic curve prescribed in ISO834 [30], required by FTPC, was used as a basis for performance assessment. This curve has little relation to natural fires, since it keeps increasing in temperature without a cooling phase representing available fuel decrease [31]. An additional curve (NFC50) was considered in an attempt to represent exposure to a natural fire. It was derived as a hypothetical fire occurring in the cafeteria on board the example ship. This curve has been calculated following the methodology proposed in [32]. The necessary input parameters are chosen as a combination of case-specific values and conservative mean values from the available literature. It has been assumed that $50 \%$ of windows in the cafeteria 
broke from the start of the fire. This natural fire curve may not represent a likely development of the fire since $50 \%$ of windows do not break from the beginning of the fire event. It is however considered more realistic than the ISO834 curve.

Exposure curves are plotted in Fig.1. The exposure curve for each test is detailed in Table 1.

The maximum exposure time was $4 \mathrm{~h}$. This duration is longer than the 60 min prescribed in the FTPC, and was chosen to compare the effect of the cooling phase of the natural curve with the steady temperature growth of ISO834. Exposure time could be shorter due to specimen failure.

\section{Loading}

In all tests in-plane compression loading was applied to the specimen. Three hydraulic jacks pressed on a beam at the top of the specimen, distributing the load uniformly over its width (Fig.2). Load was applied aligned with the centre of gravity to avoid eccentricity, in 2-3 steps depending on the utilisation percentage of the specimen capacity. Between each step it was ensured that load and deflection measurements were stable. The furnace was turned on after application of the full load. A uniformly distributed load of $7 \mathrm{kN} \cdot \mathrm{m}^{-1}$ was applied on all specimens tested with the standard ISO834 curve, as specified in the FTPC. When tested under NFC50 exposure, specimens were loaded to $50 \%$ of their Euler buckling load to represent cases with more severe mechanical loading. Loading conditions for each configuration tested with NFC50 are detailed in Table 2. Loading conditions for each individual test are detailed in Table $\mathbf{1 .}$

For the chosen location in the ferry the design load is $19.1 \mathrm{kN} . \mathrm{m}^{-1}$, calculated according to [33]. This load is independent of the bulkhead material and relates solely to the location and arrangement of the surrounding structure. The global Euler buckling load of each bulkhead has been calculated for the support conditions imposed by the FTPC, which differ from those of the design procedure, resulting 
in 36,123 , and $510 \mathrm{kN} . \mathrm{m}^{-1}$ for FRP, aluminium, and steel bulkheads respectively. It has been chosen to set the same utilisation percentage of the load bearing capacity for all specimens rather than the same load to specifically compare the different solutions in terms of load bearing capacity. The available loading equipment had a maximum capacity of 40 tons, limiting the maximum utilisation of steel bulkheads to $26 \%$ of their capacity. As a result they were loaded with $134 \mathrm{kN} \cdot \mathrm{m}^{-1}$.

\subsection{Test specimens}

Equilibrium moisture content was reached by testing day. The test specimens presented two deviations from the requirements of the FTPC for FRD, namely insulation on the exposed side only and exposure to fire from the stiffened side as this allowed other measurements not presented herein. Specimen nomenclature is presented in Table 1; their geometries and thermocouple placement are shown in Fig.2.

Steel specimens

Two identical steel specimens were prepared, following the existing structural drawings of the ferry. Both had dimensions of 2930 x $3120 \mathrm{~mm}^{2}$ (W x H) with a $6.5 \mathrm{~mm}$ plate thickness. Mannstaedt bulb flat steel stiffeners of dimensions $100 \times 7 \mathrm{~mm}^{2}$ were welded on the plate. Stiffeners were placed 700 $\mathrm{mm}$ from each other, centre to centre. Flat steel bars of dimensions $120 \times 2930$ x $10 \mathrm{~mm}^{3}$ were welded at top and bottom to offer loading and support surfaces. The steel constructions were insulated against fire using Alkaline Earth Silicate (AES) mineral wool FireMaster Marine Plus produced by Morgan Advanced Materials with a nominal density of $64.0 \mathrm{~kg} \cdot \mathrm{m}^{-3}$ (measured at $75.0 \mathrm{~kg} . \mathrm{m}^{-3}$ ) and thermal conductivity of $0.0319 \mathrm{~W} \cdot \mathrm{m}^{-1} \cdot \mathrm{K}^{-1}$ (manufacturer's data). The insulation was placed on one side only, in a $50 \mathrm{~mm}$ layer on the steel plate between stiffeners, and an additional $25 \mathrm{~mm}$ layer covering plate 
and stiffeners. Insulation was fixed with $\varnothing 3 \mathrm{~mm}$ steel pins and $\varnothing 30 \mathrm{~mm}$ steel washers placed at regular intervals.

\section{Aluminium specimens}

Two identical aluminium specimens were manufactured according to DNV's rules for aluminium hull [34]. Both had dimensions of $2930 \times 3120 \mathrm{~mm}^{2}$ with a $6 \mathrm{~mm}$ plate thickness. The plate was stiffened using aluminium angle bars of dimensions $80 \times 40 \times 6 \mathrm{~mm}^{3}$. Stiffeners were placed $700 \mathrm{~mm}$ from each other, centre to centre. Flat aluminium bars of dimensions 100 x 2930 x $10 \mathrm{~mm}^{3}$ were welded at top and bottom to offer loading and support surfaces. The same FireMaster fire insulation as for steel specimens was used, with a density of $70 \mathrm{~kg} \cdot \mathrm{m}^{-3}$ (measured at $74.4 \mathrm{~kg} \cdot \mathrm{m}^{-3}$ ) and thermal conductivity of $0.0319 \mathrm{~W} \cdot \mathrm{m}^{-1} \cdot \mathrm{K}^{-1}$ (manufacturer's data). The insulation was placed on one side only in a single layer of $50 \mathrm{~mm}$ covering plate and stiffeners. Insulation was fixed using $\varnothing 3 \mathrm{~mm}$ aluminium-tipped steel pins and $\emptyset 30 \mathrm{~mm}$ washers placed at regular intervals.

FRP specimens

Two identical sandwich specimens were designed following DNV's rules for composite hull [35]. Both had dimensions of 2930 x $3144 \mathrm{~mm}^{2}$ with $1.5 \mathrm{~mm}$ thick GFRP facesheets framing a $40 \mathrm{~mm}$ PET core. The GFRP facesheets were prepared using GBX 450L-1250 E-glass stitched fabric by DIPEX, impregnated with epoxy resin PRIMETM $20 \mathrm{LV}$ from Gurit. The fibre volume fraction was $50 \%$ and the density of the GFRP facesheets was $1851.5 \mathrm{~kg} \cdot \mathrm{m}^{-3}$. The GFRP facesheets were produced by vacuum-assisted transfer moulding and cured $16 \mathrm{~h}$ at $50^{\circ} \mathrm{C}$. The core material was the PET-based Divinycell P100 produced by DIAB of nominal density $110 \mathrm{~kg} \cdot \mathrm{m}^{-3}$ and thermal conductivity 0.033 $\mathrm{W} \cdot \mathrm{m}^{-1} \cdot \mathrm{K}^{-1}$. The sandwich bulkhead layups were symmetric, consisting of $[ \pm 45]$ facesheets and a 40 mm core. All material properties are manufacturers' data. 
The FRP bulkheads did not have stiffeners. Plywood sheets of $22 \mathrm{~mm}$ thickness were fixed at top and bottom to stiffen loading and support regions [36].

The same FireMaster fire insulation as for the steel and aluminium bulkheads was used, assembled in the sequence recommended by Morgan Advanced Materials for the protection of FRP bulkheads. Additional layers of aluminium foil were placed as extra protection against radiation. The total insulation thickness was $100 \mathrm{~mm}$ layered in the following sequence:

- $\quad 25$ mm FireMaster Marine Plus with aluminium foil, 75 kg.m ${ }^{-3}$ (measured)

- $\quad 2$ x 25 mm FireMaster Marine Plus with aluminium foil, $74.4 \mathrm{~kg} . \mathrm{m}^{-3}$ (measured)

- 25 mm FireMaster Marine Plus, 75 kg.m $\mathrm{m}^{-3}$ (measured)

Insulation was fixed tightly with $\emptyset 3 \mathrm{~mm}$ steel pins and $\emptyset 38 \mathrm{~mm}$ steel washers. Pins were drilled and anchored in the composite facesheets.

\subsection{Monitoring}

Temperatures at various locations in the specimens were recorded using regular type $\mathrm{K}$ thermocouples with a precision of $\pm 2^{\circ} \mathrm{C}$, prepared in accordance with [29]. For steel and aluminium specimens, thermocouples were mounted on the stiffeners on the exposed side, and on the unexposed surface. For the FRP specimens, thermocouples were fixed on the facesheet on the exposed side, others were drilled into the core material, and others were fixed on the unexposed surface, to measure temperature gradients.

For all bulkheads, deflections were measured using an array of strings fixed to the unexposed surface. The strings were connected via fishing wheels to a data logger recording displacements. Sensors embedded in the hydraulic jacks monitored the applied load during testing. The experiments were performed under load control. 


\section{TEST RESULTS}

Recorded experimental temperature exposure curves are presented in Fig.1 along with their theoretical counterparts. They are in very good overall agreement. Temperature recordings at the same position (fire side, unexposed side) gave consistent results between repeated measurement points; the graphs therefore present average values of several thermocouples at the same position.

The laboratory where tests were performed took part in surveys assessing its level of repeatability for full scale resistance-to-fire tests; this level was found within the $95 \%$ mark. This number is particularly valid for simple constructions such as steel and aluminium bulkheads. As an accredited body the laboratory is not allowed to disclose these results. In the case of the composite bulkhead, the level of repeatability could be expected lower due to the higher complexity of the material, manufacturing process, small thickness of the laminate layers, and influence of the deformations on the exposed surface due to the change in geometry on that side.

\subsection{Overall performance}

An overview of the test results is presented in Table 3. Steel bulkheads passed all tests, whereas aluminium and FRP bulkheads experienced failures. The FRP bulkheads failed mechanically before the maximum exposure time of $4 \mathrm{~h}$.

ISO834 exposure

In terms of the FTPC requirements, applicable to the standard ISO834 exposure, only the aluminium bulkhead failed, on the insulation criterion at $58 \mathrm{~min}$ (rise of $143^{\circ} \mathrm{C}$ at $60 \mathrm{~min}$ ). The other bulkheads passed the 60 min test, potentially fulfilling the requirements for FRD60 classification. The robustness of the structures was assessed by continuing the test for up to $4 \mathrm{~h}$. In this case, metallic bulkheads 
showed no sign of collapse, whereas the FRP bulkhead failed mechanically at $82 \mathrm{~min}$. No specimen showed integrity breach.

\section{NFC50 exposure}

This curve was used primarily to highlight the mechanical resistance of each bulkhead type during the cooling phase. Unexposed side temperatures at $60 \mathrm{~min}$ are given to compare with ISO834 results. From a mechanical standpoint, steel and aluminium bulkheads passed the NFC50 test for an exposure time of $4 \mathrm{~h}$. Concerning the insulation criterion from the FTPC, both metallic bulkheads remained below $140^{\circ} \mathrm{C}$ on the unexposed surface after $60 \mathrm{~min}$ of exposure to NFC50.

The FRP bulkhead failed mechanically after $61 \mathrm{~min}$, before the NFC50 curve reached its cooling phase. It could however fulfil the insulation criterion from the FTPC when exposed to the NFC50 curve, displaying a temperature rise on the unexposed side of $6^{\circ} \mathrm{C}$ after $60 \mathrm{~min}$ of exposure.

\subsection{Temperature recordings}

\section{Metallic bulkheads}

Steel and aluminium bulkheads behaved similarly with respect to temperature, with differences inherent to their respective thermal properties. Temperature rose very quickly on the fire side for the steel bulkhead exposed to the ISO834 temperature curve, since only $25 \mathrm{~mm}$ of insulation protected the stiffeners. It led to the hottest fire side of all tested specimens in the case of the ISO834 exposure curve, hotter than aluminium which tends towards equilibrium faster (Fig.3). Recordings on the fire side of the steel bulkhead in the case of the NFC50 curve show very low values. For this test, thermocouples were mounted by drilling from the unexposed surface to be inserted at the tip of stiffeners. Measurement occurs at the first contact point between thermocouple wire and bulkhead. This point could have been unintentionally located closer to the unexposed surface due to the 
mounting procedure, leading to lower recorded temperatures. Uncertainty in measurement location implies that these results should be disregarded in the following.

Steel specimens present lower unexposed side temperatures than the aluminium ones for all tests. For the ISO834 test, the steel specimen remained below the prescribed rise of $140^{\circ} \mathrm{C}$ for $116 \mathrm{~min}$, when the aluminium counterpart failed at $58 \mathrm{~min}$. With the NFC50 curve, unexposed side temperatures rose of a maximum of $141^{\circ} \mathrm{C}$ and $169^{\circ} \mathrm{C}$ for steel and aluminium specimens respectively, making steel perform close to prescriptive requirements even for a natural curve. In the case of natural fire curves steel exhibits slower cooling than aluminium (Fig.3) highlighting its higher thermal inertia.

Fire side temperature curves for ISO834 exposure show a slight jump at $140 \mathrm{~min}$ (Fig.3) corresponding to furnace manipulations. The same jump is visible on the exposure curves (Fig.1).

\section{FRP bulkheads}

Fire side temperatures of FRP bulkheads remained constant during the first 22 to 25 min due to the $100 \mathrm{~mm}$ insulation layer. The temperature then increased suddenly and more steeply than for aluminium or steel specimens (Fig.3). It was particularly visible for NFC50 exposure. Unexposed side temperatures reached $35^{\circ} \mathrm{C}$ for ISO834 exposure, and $23^{\circ} \mathrm{C}$ for NFC50 exposure (Fig.3).

Failure occurred sooner and at lower temperatures for NFC50 exposure than for ISO834 exposure

(Table 3). Representative values of $\mathrm{T}_{\mathrm{g}}$ for PET are given in [37]. At failure time for NFC50 exposure, temperatures recorded in the core material remained below its $\mathrm{T}_{\mathrm{g}}$ of $80^{\circ} \mathrm{C}$. At the same locations, temperatures were recorded above $\mathrm{T}_{\mathrm{g}}$ for ISO834 exposure (Fig.4). The same graph shows that most of the heat is concentrated in the first $10 \mathrm{~mm}$ of the thickness for both tests.

On individual recordings on the fire side facesheet of the FRP bulkheads, a sudden temperature jump is visible (Fig.5). This takes place between $45-55 \mathrm{~min}$ and $100-180^{\circ} \mathrm{C}$ for ISO834 exposure, and 
between $58-61 \mathrm{~min}$ and $140-180^{\circ} \mathrm{C}$ for NFC50 exposure. No counterpart is visible on the unexposed side, and no change in exposure curves corresponds to this observation.

\subsection{Deformation measurements}

\section{Metallic bulkheads}

Deflections follow the trend of the exposure curve. During the heating phase, specimens deflect towards the heat (positive slope) and retract away from it (negative slope) during the cooling phase. Steel bulkheads show larger deflections at the centre than at the edges at early exposure times, which reverses after 100 min of both ISO834 and NFC50 exposure (Fig.6). Aluminium specimens show 2 to 5 times higher deflections at the centre than at the edges for ISO 834 and NFC50 exposure respectively. Steel deflects much more than aluminium, both at similar load levels (ISO834) and at lower capacity usage (NFC50).

\section{FRP bulkheads}

During the first minute after test start, the structure deflected away from the heat source. This originates from overpressure in the furnace generated by burner ignition pushing the specimens outwards.

Deflections started after 30 min of exposure (Fig.6), following the necessary time for heat to penetrate the insulation layer (i.e. 22-25 min) (Fig.3). Deflections then increased towards the heat with a slope generally steeper than for steel and aluminium bulkheads.

In the case of exposure to ISO834 curve, deflections reached a first peak after $40 \mathrm{~min}\left(72^{\circ} \mathrm{C}\right.$ on fire side facesheet) followed by a decrease (specimen retracts away from heat) until $47 \mathrm{~min}\left(100^{\circ} \mathrm{C}\right.$ on fire side facesheet), and then rose again with a steeper slope than the initial one (Fig.6a). A second 
deflection peak was reached after $73 \min \left(245^{\circ} \mathrm{C}\right.$ on fire side facesheet $)$ followed by a strong decrease before the specimen failed after $82 \mathrm{~min}\left(300^{\circ} \mathrm{C}\right.$ on fire side facesheet $)$.

When exposed to the NFC50 curve, the FRP bulkhead exhibited similar deflections (Fig.6b) with the appearance of a peak at $42 \mathrm{~min}\left(73^{\circ} \mathrm{C}\right.$ on fire side facesheet). No deflection decrease was recorded, rather a short plateau before a steep, almost vertical deflection increase towards the heat, and ultimately failure at $61 \mathrm{~min}\left(162^{\circ} \mathrm{C}\right.$ on fire side facesheet $)$.

Before the first inflection point in the deflection-time curve the FRP bulkheads deflected less than metallic counterparts. Failure was then reached in an unstable fashion due to buckling.

\subsection{Failure modes}

Steel bulkheads did not experience structural failure in any of the tests. Aluminium bulkheads maintained their load-carrying capacity in both tests, though plate buckling was noted for the NFC50 exposure.

FRP bulkheads reached failure after $82 \mathrm{~min}$ for FRP1 and $61 \mathrm{~min}$ for FRP2 (ISO834 and NFC50 exposure respectively). The deformed shape at failure was more pronounced on FRP1 but similar for both FRP specimens, representing global buckling of the structure (Fig.7). The bulkheads deflected towards the furnace, but the bottom part close to the support remained vertical due to the imposed boundary conditions (clamped).

Specimen FRP2 was cut after testing for better inspection. At the lower end of the bulkhead which was clamped, the fire side FRP facesheet showed a large debonded section with a facesheet/core debonding width of $0.3 \mathrm{~m}$ (Fig.8 left). The debonded zone formed a well-marked crack running on the full width of the specimen in a saw-tooth pattern (Fig.8 right). The crack tip showed delamination of the facesheet layers with local disappearance of the matrix (Fig.8 left). The lower half of the exposed 
side of the specimen turned darker than the upper half, suggesting more heat was located in the lower part of the furnace. No trace of mechanical failure was observed in the FRP facesheet on the unexposed side; post-test examinations revealed an intact facesheet/core interface. No trace of mechanical failure could be observed in the core material.

No observation of surface states and facesheet/core interaction could be performed on FRP1. Insulation fell off the FRP facesheet during post-test handling leading to immediate ignition and sustained flaming of the polymer matrix and core material due to incoming oxygen. Interestingly, it was visible on specimen FRP1 that when the core heated up without burning, the melting led to a thickness reduction of the sandwich element suggesting loss of facesheet/core bonding and thus significant loss of stiffness, possibly during the test as well. The bond was reinstated after cooling.

\section{DISCUSSION}

All three constructions passed the test according to the FTPC with ISO834 exposure, fulfilling the necessary criteria for FRD60 classification. Results beyond 60 min of exposure highlight that the performance of the individual structures in terms of fire hazard varies widely, particularly in terms of structural integrity.

\subsection{Temperatures}

\section{Insulation performance}

The unexposed side temperature of the FRP bulkheads remained close to ambient even after 80 min of exposure to heat, unlike the metallic counterparts (Fig.3). Steel and aluminium are highly thermally conductive metals whereas FRP bulkheads are made of thermally resistive materials hindering heat conduction to the unexposed surface. Additionally, the thickest fire insulation layer was applied to the FRP bulkheads (Table 1), increasing their thermal insulation capabilities. For a comparable total 
thickness (bulkhead + thermal insulation) (Table 1) FRP bulkheads display a superior ability to act as thermal barrier whereas metallic bulkheads do not prevent heat conduction efficiently, thus increasing the risk of fire spread.

The thicker insulation layer applied on steel and the thermal properties of the metals can explain temperature differences between steel and aluminium bulkheads, slowing down the energy transfer from the furnace environment. Aluminium has a higher thermal conductivity and lower heat capacity than steel. This leads to quick transport of heat towards the unexposed surface, hence the lower exposed side temperature and faster unexposed side temperature build-up observed for aluminium. Temperature gradients in aluminium are limited since it cannot store heat efficiently. The strong insulation performance of the FRP bulkheads leads to a sharp temperature build-up on the exposed side once the heat front penetrates the insulation layers and reaches the facesheets. The temperature difference between the exposed side facesheet and the thermocouple located $10 \mathrm{~mm}$ inside the core material is large $\left(180^{\circ} \mathrm{C}\right.$ and $140^{\circ} \mathrm{C}$ at failure time for ISO834 and NFC50 exposures, respectively) (Fig.4), suggesting that most of the energy is stored in this small volume of the structure. Paradoxically, being made of thermally resistive materials, the FRP bulkheads cannot dissipate heat to their surroundings and temperatures rise above the critical $\mathrm{T}_{\mathrm{g}}$ of the matrix. This leads to degradation of the load-carrying capacity and will be elaborated further.

\section{Epoxy degradation}

The exposed side facesheet temperature on the FRP bulkheads rises up to $300^{\circ} \mathrm{C}$ for ISO834 exposure and $200^{\circ} \mathrm{C}$ for NFC50 exposure (Fig.4). These temperatures are significantly higher than the glass transition temperature of the epoxy matrix in the FRP material, which is typically in the vicinity of 
$70^{\circ} \mathrm{C}$. For the laminate making up the facesheet it has been measured in preceding experiments that the mechanical properties degrade by around $50 \%$ at temperatures as low as $62.5^{\circ} \mathrm{C}[38]$.

Early stages of epoxy degradation can be expected as endothermic reactions as heat is consumed to break the polymer chains; unless ignition occurs in which case energy is released. However, no temperature plateau is visible in the temperature recordings from the fire side facesheets. On the contrary, the individual temperature recordings show a sudden rise between $100-180^{\circ} \mathrm{C}$ which stabilises in a constant positive slope (Fig.5). In this early phase, moderate amounts of pyrolysis gases are released from the facesheet at an almost constant rate $[\mathbf{3 9 , 4 0 ]}$. These gases could ignite in the thin layers of air present at the facesheet/insulation interface, raising temperature abruptly. As the reaction is maintained by incoming heat, gases are consistently produced and temperature keeps increasing at a steady rate. The temperature difference at the onset of the slope changes between ISO834 and NFC50 exposures could be attributed to the slower temperature build-up of the NFC50 curve which supplies less energy in a given time.

For ISO834 exposure, a second temperature rise is visible on some curves around $275^{\circ} \mathrm{C}$ (Fig.5, left), suggesting the epoxy matrix may enter the decomposition phase. This is supported by values of the degradation temperature $\mathrm{T}_{\mathrm{d}}$ reported around $300^{\circ} \mathrm{C}$ in the literature [39-41]. It correlates well with the onset of severe slope changes on differential scanning calorimeter (DSC) curves $[\mathbf{3 9 , 4 0 ]}$.

Epoxy matrix degradation could be one more mechanism benefiting the insulation performance of FRP bulkheads, since the process is endothermic. However, the possible ignition of subsequently produced pyrolysis gases could lead to additional heat production deteriorating the structure. 


\subsection{Deflections and loading}

Deflections - general considerations

All specimens show larger deflections in the centre than at the edges resulting from the applied boundary conditions in conjunction with thermal bowing (Fig.6). This pattern gets reversed for steel bulkheads after some time, no explanation could be found for this behaviour.

Steel and aluminium bulkheads have the same dimensions, except for shorter stiffeners on aluminium bulkheads. Moments of inertia can be expected to be similar, possibly lower for aluminium bulkheads. However, steel has a higher E-modulus than aluminium. At similar load levels aluminium bulkheads could therefore be expected to deflect more than their steel counterparts. Steel has a thermal expansion coefficient of $12.8 \times 10^{-6} \mathrm{~K}^{-1}$ [42], aluminium of $24 \times 10^{-6} \mathrm{~K}^{-1}$ [43], and E-glass laminate between 4.9 and $6 \times 10^{-6} \mathrm{~K}^{-1}$ according to the manufacturing method (values may vary with the choice of polymer matrix) [44]. Despite a higher thermal expansion coefficient and lower E-modulus, aluminium bulkheads deflect less than steel bulkheads due to their lower exposed side temperature. This could represent a mechanical advantage by limiting the heat-induced eccentricity in load application, allowing for a design closer to the limit of the bulkhead capacity.

Deflections for FRP bulkheads start later than steel and aluminium bulkheads due to thicker insulation. They present steeper slopes once heating starts, despite their low thermal expansion. Thermal expansion therefore cannot explain this observation. However, epoxy loses strength at low temperature, leading to non-uniform degradation of the mechanical properties of the bulkhead, reducing its load-carrying capacity. FRP bulkhead deformations appear mainly driven by mechanical loading under the influence of heat on mechanical properties.

\section{Deflections in FRP bulkheads}


Local maxima are visible on the deflection curves for the FRP bulkheads for both exposure curves (Fig.6). Epoxy is a thermoset and most thermosets degrade under the effect of temperature following a 2-step decay. The two steps mark the transitions from glassy to rubbery and from rubbery to decomposed states, respectively $[\mathbf{1 5 , 4 5}]$. Bai et al. [15] observed a 2-step decay of the E-modulus of the thermoset matrix (polyester in their case) with slope changes corresponding to $T_{g}$ and $T_{d}$. $T$ he epoxy used in the present study has $\mathrm{T}_{\mathrm{g}}$ estimated around $70^{\circ} \mathrm{C}$, and its degradation temperature is unknown but most epoxies have $\mathrm{T}_{\mathrm{d}}$ around $300^{\circ} \mathrm{C}$ [39-41]. The first local maximum in the deflection curve for the FRP bulkheads occurs at 72 and $73^{\circ} \mathrm{C}$ (fire side temperature) for ISO834 and NFC50 exposures respectively, which correlates with the later stages of glass transition. The second peak, visible only for ISO 834 exposure (longer exposure time), occurs at $245^{\circ} \mathrm{C}$, close to the reported degradation temperature of epoxies. These peaks coincide well with significant changes in material properties of the exposed facesheet, which could correlate with E-modulus reduction as reported in [15] for polyester, impacting the deflections of the bulkhead.

The retreat of the bulkhead away from heat (negative slope of deflection curve) could illustrate a shift in the load distribution in the FRP bulkhead. The reduction of the E-modulus of the fire side facesheet would lead to a load transfer towards the non-degraded unexposed facesheet. Facesheet/core interaction may be weakened as temperature recordings suggest (Fig.4), resulting in a decrease of shear transfer between the layers of the sandwich structure. This shift could lead to additional loading eccentricity and to the development of bending moments due to the displacement of the neutral axis of the structure, ultimately overloading the unexposed facesheet to reach buckling failure. Detailed investigations and verification of the sequence of events resulting in these deflections will be the object of a further publication. 


\section{Structural behaviour and loads}

The linear load applied on specimens exposed to the ISO 834 curve is relevant within the scope of the HSC Code. However, this paper focuses on SOLAS vessels. Specimens tested with NFC50 exposure were subjected to increased load levels to represent more generic situations. Steel bulkheads could be loaded to only $26 \%$ of their Euler buckling load $\left(134 \mathrm{kN} \cdot \mathrm{m}^{-1}\right)$ with the available equipment. At that level of loading, the Euler buckling threshold of both aluminium and FRP bulkheads would have been exceeded (Table 2). Aluminium and FRP bulkheads were loaded to $50 \%$ of their respective Euler buckling load. This represents a linear load of $18 \mathrm{kN} \cdot \mathrm{m}^{-1}$ for the composite bulkhead, more than 7 times lower than the load applied on the steel bulkhead. Since all bulkheads were designed for use in the same conditions they should all resist the same operational load, calculated equal to $19.1 \mathrm{kN} \cdot \mathrm{m}^{-1}$ with service support conditions. This corresponds to $3.5 \%$ of the Euler buckling load of the steel bulkhead, which could therefore lose more than $95 \%$ of its strength and still keep its ability to carry this load. The maximum temperature recorded on steel specimens was $662^{\circ} \mathrm{C}$ after $3.5 \mathrm{~h}$ of exposure to the ISO 834 curve, at which $30 \%$ of the yield strength and $40 \%$ of E-modulus were still available [42].

These results suggest that metallic bulkheads may have been significantly over-dimensioned with respect to their buckling capacity. However, in reality, structural design must satisfy multiple criteria related to the operation and production aspects of such elements, which may be the reason why these structures appear to be overdesigned. On the contrary, FRP bulkheads tend to be optimised in order to represent a viable and favourable solution in terms of weight savings and material costs. 


\subsection{Robustness and design}

A universally accepted definition of robustness has yet to be introduced. Robustness was defined in the beginning of this paper as the ability of a structural element to maintain its load-carrying capacity when exposed to elevated temperatures. Robustness is implicit in nature since it is beyond the scope of standard tests, therefore deemed unquantifiable. In the presented test results, robustness was quantified as the time elapsed until the loss of load-carrying capacity of the tested bulkheads under the specific test conditions. The FRP bulkheads reached mechanical failure after 82 and 61 min for ISO834 and NFC50 exposures respectively. This allows giving a robustness time frame and provides quantified information on the behaviour of a given structure. Moreover, it highlights the critical importance of defining a fire scenario representative of real-life thermomechanical loading combinations to assess robustness. In fact, the NFC50 scenario was closer to reality and led to quicker failure of the FRP bulkhead. Robustness could not be documented for steel bulkheads as they did not reach failure despite $4 \mathrm{~h}$ of heat exposure. This was attributed to the good thermal resistance of steel and to the grossly overdesigned solution.

The FTPC test considers only one default scenario, which does not represent a realistic situation. Several issues have been highlighted above, such as unrealistic fire exposure, severely underestimated in-plane mechanical loading, and different boundary conditions from these of real-life constructions. It follows that the behaviour of structures outside the strict scope of the FTPC test is not assessed. This test procedure allows ranking solutions against each other, but does not assess whether a given design is adapted to the desired application. It is therefore questionable whether the robustness observed in this test can at all document what could be expected of a FRP structure on board a SOLAS ship. 
The previous discussion highlighted the fundamentally different behaviour of metallic and FRP bulkheads at high temperatures. Metallic solutions conduct heat whereas composites resist it and accumulate it on the exposed side (Fig.3 and 4). Deflections in FRP bulkheads are governed by highly non-linear thermo-mechanical phenomena (Fig.6). Degradation of the mechanical properties of steel and aluminium occurs at much higher temperatures than composites; they are therefore less sensitive to heat than composites, from a structural standpoint. Different properties should motivate different design procedures to achieve suitable robustness. Current steel design practice focusses on ambient condition performance, then an insulation layer calculated to satisfy FTPC requirements protects against fire. This traditional approach is also applied to lightweight designs, specifically composites, which are optimised for standard operational conditions. However the role of the insulation layer differs for metallic and FRP solutions due to the behaviour of the materials at elevated temperatures. For metallic bulkheads the heat transfer to the unexposed side should be limited to prevent fire spread. For composites, ignition should be prevented and strength loss delayed for the duration of the classification test. In both cases insulation type and thickness are the design results. It is apparent that the same approach is followed to target two very different problems. As a result, poor robustness is achieved for FRP solutions which still do not fulfil SOLAS fire safety objectives, which is usually documented by showing an equivalent level of safety as for a steel solution. These observations suggest that the specific properties of FRP bulkheads must be used for design. Since their sensitivity to heat directly impacts their strength and therefore the robustness of the structure, it is suggested that well-defined fire situations are used as design scenarios for FRP bulkheads considered for SOLAS vessels. 
The question of what constitutes a suitable robustness target still remains. The definition of such a global criterion is problematic. For instance a worst-case scenario could be defined through a risk analysis [46] and the structure assessed for the entire duration of the corresponding fire. Alternatively, a time target for the ISO834 could be discussed specifically for robustness, though this seems unlikely with respect to extremely long time durations. The discussion should be carried on for this point.

\section{CONCLUSION}

The present work showed that designing structural elements for a SOLAS vessel using FRP materials and complying with the existing regulations could be possible. Nevertheless, an additional requirement regarding the load-carrying capacity of structural elements exposed to fire well beyond the timeframe prescribed by regulations stems from SOLAS Chapter 2-II Regulation 17 stipulating that an equivalent level of safety to that achieved with steel construction must be ensured. This additional requirement is referred to as robustness, and is considered among the main reasons behind the scepticism surrounding the implementation of FRP on SOLAS vessels.

This work highlighted that currently the rules covering FRP implementation are based on existing regulations for steel structures, and as such fail to take into consideration the particularities of composite structures. In the presented tests, metallic designs did not fail on the robustness criterion due to their limited thermal degradation at the temperatures involved and their significantly overdesigned nature. FRP bulkheads failed mechanically in both scenarios due to the substantial decrease of their mechanical properties and optimised design resulting in lower safety margins. This research found that properties of lightweight materials at elevated temperatures, specifically FRP, are disregarded when designing. They should be carefully accounted for, as besides the degradation of their mechanical properties they also offer advantages, such as efficient protection 
against heat conduction resulting in the potential to contain the fire to the compartment of origin. It follows that for composite materials, the standard operational situation cannot be used as a design scenario. A major finding is that fire situations should be regarded as the dimensioning criterion. Designing with composite materials allows for purpose-built solutions. In order to achieve acceptable performance and level of safety in a fire situation, the robustness of the structure must be quantified and used as a design objective. This is a difficult undertaking as many parameters are involved (e.g. natural fire exposure, loading, effect of surrounding structures) and would therefore require performance-based design based on a thorough risk analysis.

Such an approach faces the challenging and controversial task of defining acceptable levels of safety. As composite materials are heat sensitive and provide custom solutions, the safety provided varies according to the design choices. If it is believed that designing for a given level of safety is possible, it remains to define what is considered and accepted as "safe enough". The question is of importance, and will have to be addressed to include alternative materials for structural applications on board ships.

\section{ACKNOWLEDGEMENTS}

The research leading to these results was performed under the scope of the COMPASS project, funded by the Danish Maritime Authority and the Danish Maritime Fund. The authors would like to gratefully acknowledge DIAB for sponsoring the core material, Morgan Thermal Ceramics for sponsoring the insulation, and the support from Niels Hjørnet, Søren Rud Pedersen, and Ufuk Veli Ceylan for their participation in the design, conduction, and evaluation of the experiments. 


\section{REFERENCES}

[1] IMO. International Convention for the Prevention of Pollution from Ships (MARPOL).

Consolidated Edition 2011, amended September 2015.

[2] Armstrong VN, Banks C. Integrated approach to vessel energy efficiency. Ocean Eng 2015;110:39-48.

[3] Lepistö V, Lappalainen J, Sillanpää K, Ahtila P. Dynamic process simulation promotes energy efficient ship design. Ocean Eng 2016;111:43-55.

[4] Hertzberg T. Lightweight Construction Application at Sea (LASS). SP Report 2009:13.

[5] Fiore V, Di Bella G, Valenza A. Glass-basalt/epoxy hybrid composites for marine applications. Mater Design $2011 ; 32: 2091-2099$.

[6] Pham DC, Sridhar N, Qian X, Sobey AJ, Achintha M, Shenoi A. A review on design, manufacture and mechanics of composite risers. Ocean Eng 2016;112:82-96.

[7] Evegren F. Breakthrough in European Ship and Shipbuilding Technologies (BESST) Engineering analysis report - Norwegian Future. SP Report 2015:03.

[8] Berg AC, Bank LC, Oliva MG, Russell JS. Construction and cost analysis of an FRP reinforced concrete bridge deck. Constr Build Mater 2006;20:515-526.

[9] Ahmed A, Kodur VKR. Effect of bond degradation on fire resistance of FRP-strengthened reinforced concrete beams. Compos Part B-Eng 2011;42:226-237.

[10] Urbanski M, Lapko A, Garbacz A. Investigation on concrete beams reinforced with basalt rebars as an effective alternative of conventional R/C structures. Proceedings of the 11th International Conference on Modern Building Materials, Structures and Techniques (MBMST 2013), Vilnius, Lithuania; 16-17 May 2013

[11] Mouritz AP, Gibson AG. Fire properties of polymer composite materials. 1st ed. Dordrecht, The Netherlands: Springer; 2006.

[12] Mouritz AP. Review of smoke toxicity of fibre-polymer composites used in aircraft. J Aircraft 2009;46(3):737-745.

[13] Mouritz AP, Bannister MK, Falzon PJ, Leong KH. Review of applications for advanced threedimensional fibre textile composites. Compos Part A-Appl S 1999;30:1445-1461.

[14] Erber M, Khalyavina A, Eichhorn KJ, Voit BI. Variations in the glass transition temperature of polyester with special architectures confined in thin films. Polym 2010;51:129-135.

[15] Bai Y, Keller T, Vallée T. Modelling of stiffness of FRP composites under elevated and high temperatures. Compos Sci Technol 2008;68:3099-3106.

[16] Dimitrienko YI. Thermomechanical behaviour of composite materials and structures under high temperatures: 1. Materials. Compos Part A-Appl S 1997;28:453-461.

[17] Tracy CD. Fire endurance of multicellular panels in an FRP building system. Ph.D. thesis, Ecole Polytechnique Fédérale de Lausanne, Switzerland; 2005. 
[18] Asaro RJ, Lattimer B, Ramroth W. Structural response of FRP composites during fire. Compos Struct 2009;87:382-393.

[19] Summers PT, Lattimer BY, Case S, Feih S. Predicting compression failure of composite laminates in fire. Compos Part A-Appl S 2012;43:773-782.

[20] Gu P, Asaro RJ. Designing sandwich polymer matrix composite panels for structural integrity in fire. Compos Struct 2009;88:461-467.

[21] Hakkarainen T, Hietaniemi J, Hostikka S, Karhula T, Kling T, Mangs J, Mikkola E, Oksanen T. Survivability for ships in case of fire - Final report of SURSHIP-FIRE project. VTT Technical Research Centre of Finland Research Notes 2497, 2009.

[22] LightShip Project - Status for use of FRP in Commercial Shipbuilding. Danish Institute of Fire and Security Technology 2015

[23] International Maritime Organisation. International Code of Safety for High Speed Craft, Edition 2008.

[24] International Maritime Organisation. Code for Application of Fire Test Procedures (FTP) 2010.

[25] International Maritime Organisation. International Convention for the Safety of Life at Sea (SOLAS). Consolidated Edition 2014.

[26] Halskov L. Baggrund: "Scandinavian Star” er den største mordgåde i Skandinavien. Politiken, 6th April 2013

[27] Vairo T, Quagliati M, Del Giudice T, Barbucci A, Fabiano B. From land- to water-use-planning: A consequence based case-study related to cruise ship risk. Safety Sci 2016; in press.

[28] Dragsted A, Hulin T, Karatzas V, Berggreen C, Mindykowski PA, Jomaas G, Kristensen KL, Nielsen NB. Guideline for the use of FRP in superstructures on passenger ships. COMPASS Project, Danish Institute of Fire and Security Technology, Technical University of Denmark 2016

[29] International Maritime Organisation. Resolution MSC.307(88) for the International Code for Application of Fire Test Procedures. 3 December 2010

[30] International Standard Organisation ISO 834-1: Fire Resistance Tests

[31] Barnett CR. Replacing international temperature-time curves with BFD curve. Fire Saf J 2007;42(4):321-327.

[32] Hertz K. Guidelines for dimensioning building constructions in fully developed fire, version 2-3 (in Danish). Technical University of Denmark 2006

[33] Det Norske Veritas. Rules for Classification of Ships - Part 3 Chapter 1 - Newbuildings Hull and Equipment - Main Class - Hull Structural Design, Ships with Length 100 metres and above, 2014. [34] Det Norske Veritas. Rules for Classification of High Speed, Light Craft and Naval Surface Craft - Part 3 Chapter 3 - Hull Structural Design, Aluminium Alloy, 2012.

[35] Det Norske Veritas. Rules for Classification of High Speed, Light Craft and Naval Surface Craft - Part 3 Chapter 4 - Hull Structural Design, Fibre Composite and Sandwich Constructions, 2013. [36] Marine Composites, Second Edition, Eric Greene Associates, 1999. 
[37] Wilkes CE, Summers JW, Daniels CA, Berard MT. PVC Handbook. Hanser Verlag; 2005.

[38] Rezaei M. Material characterisation tests at elevated temperatures. COMPASS Project Annex E, Danish Institute of Fire and Security Technology, Technical University of Denmark, 2016.

[39] Schartel B, Braun U, Balabanovich AI, Artner J, Ciesielski M, Döring M, Perez RM, Sandler JKW, Altstädt V. Pyrolysis and fire behaviour of epoxy systems containing a novel 9,10-dihydro-9oxa-10-phosphaphenanthrene-10-oxide-(DOPO)-based diamino hardener. Eur Polym J 2008;44:704715 .

[40] Wang X, Hu Y, Song L, Xing W, Lu H, Lv P, Jie G. Flame retardancy and thermal degradation mechanism of epoxy resin composites based on a DOPO substituted organophosphorus oligomer. Polymer 2010;51:2435-2445.

[41] Luda MP, Balabanovich AI, Zanetti M. Pyrolysis of fire retardant anhydride-cured epoxy resins. J Anal Appl Pyrol 2010;88:39-52.

[42] Kodur V, Dwaikat M, Fike R. High temperature properties of steel for fire resistance modeling of structures. ASCE J Mat Civ Eng 2010;22:423-434.

[43] ASM Ready Reference - Thermal properties of metals. ASM International, 2002

[44] ASM Handbook Vol. 21: Composites. ASM International, 2001

[45] Hurley MJ, Gottuk DT, Hall JR Jr, Harada K, Kuligowski ED, Puchovsky M, Torero JL, Watts JM Jr, Wieczorek CJ. SFPE Handbook of Fire Protection Engineering. 5th Edition, Springer 2016. [46] Papanikolaou AD. Risk-Based Ship Design, Methods, Tools and Applications. 1st Edition, Springer 2009. 


\section{FIGURE LIST}

a. $1200-$

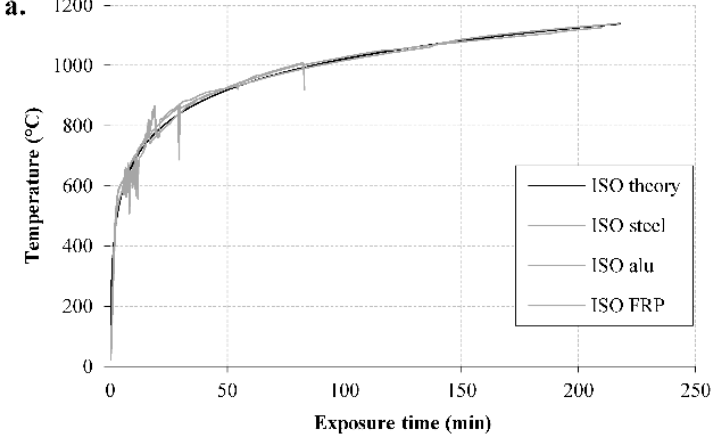

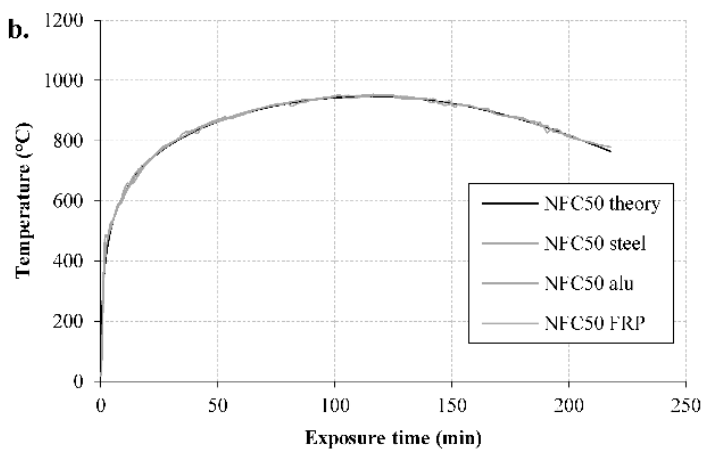

Figure 1 - Time-temperature curves used for exposure of test specimens, and comparison with furnace temperature during the tests. ISO 834 (a); NFC50 (b) 

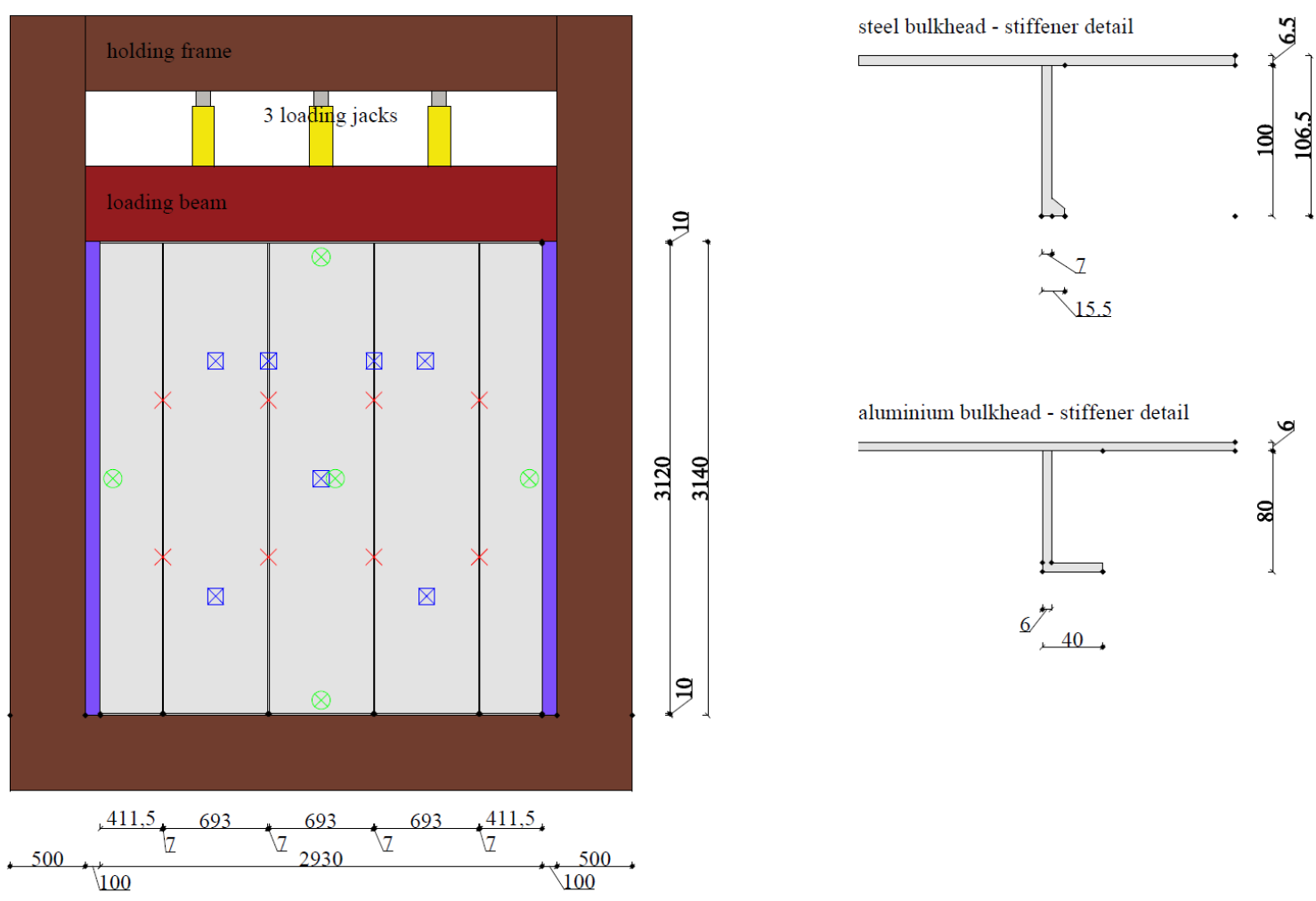

COMPOSITE BULKHEADS

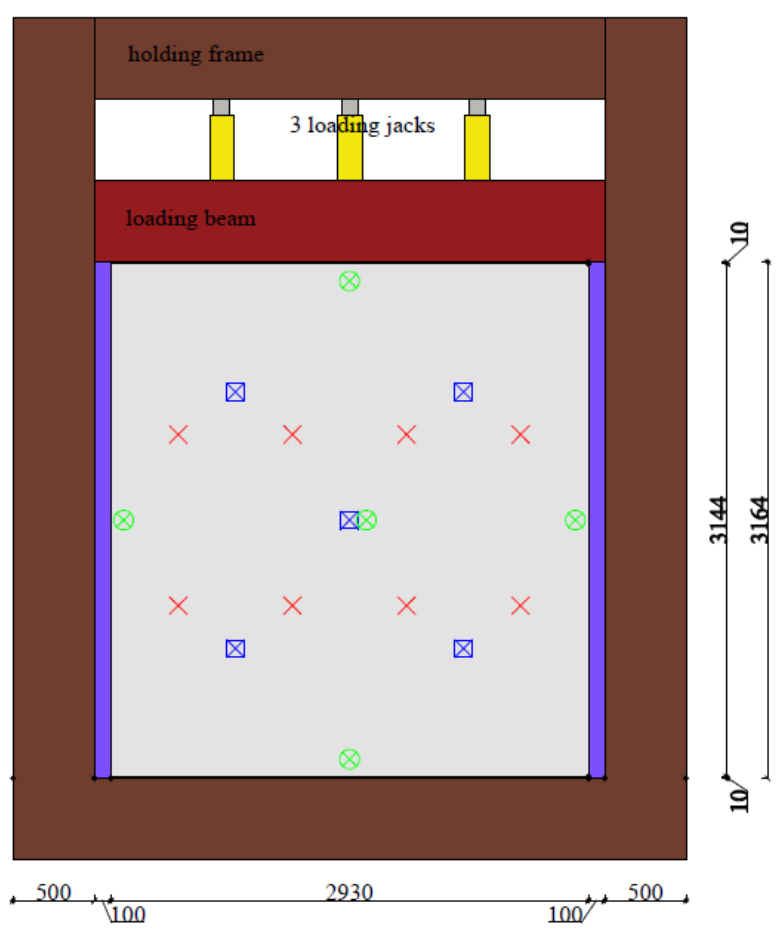

composite bulkhead - cut through the thickness and placement of thermocouples in the core material

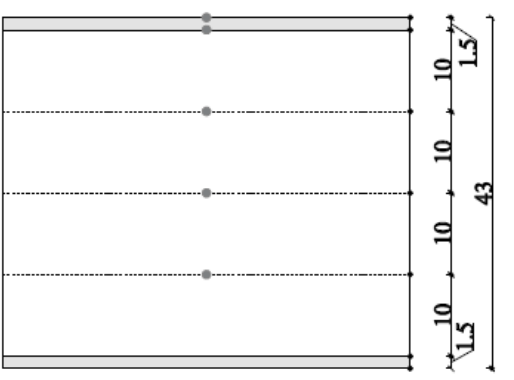

गे है

\begin{tabular}{|ll}
$X$ & exposed side thermocouples \\
$\square$ & unexposed side thermocouples \\
$\otimes$ & core thermocouples (composite panels only) \\
$\square$ & deflection measurement points \\
$\square$ & insulation between specimen and frame
\end{tabular}

Figure 2 - Geometric layout of steel, aluminium (a,b,c), and FRP specimens (d,e), and loading set-up. 

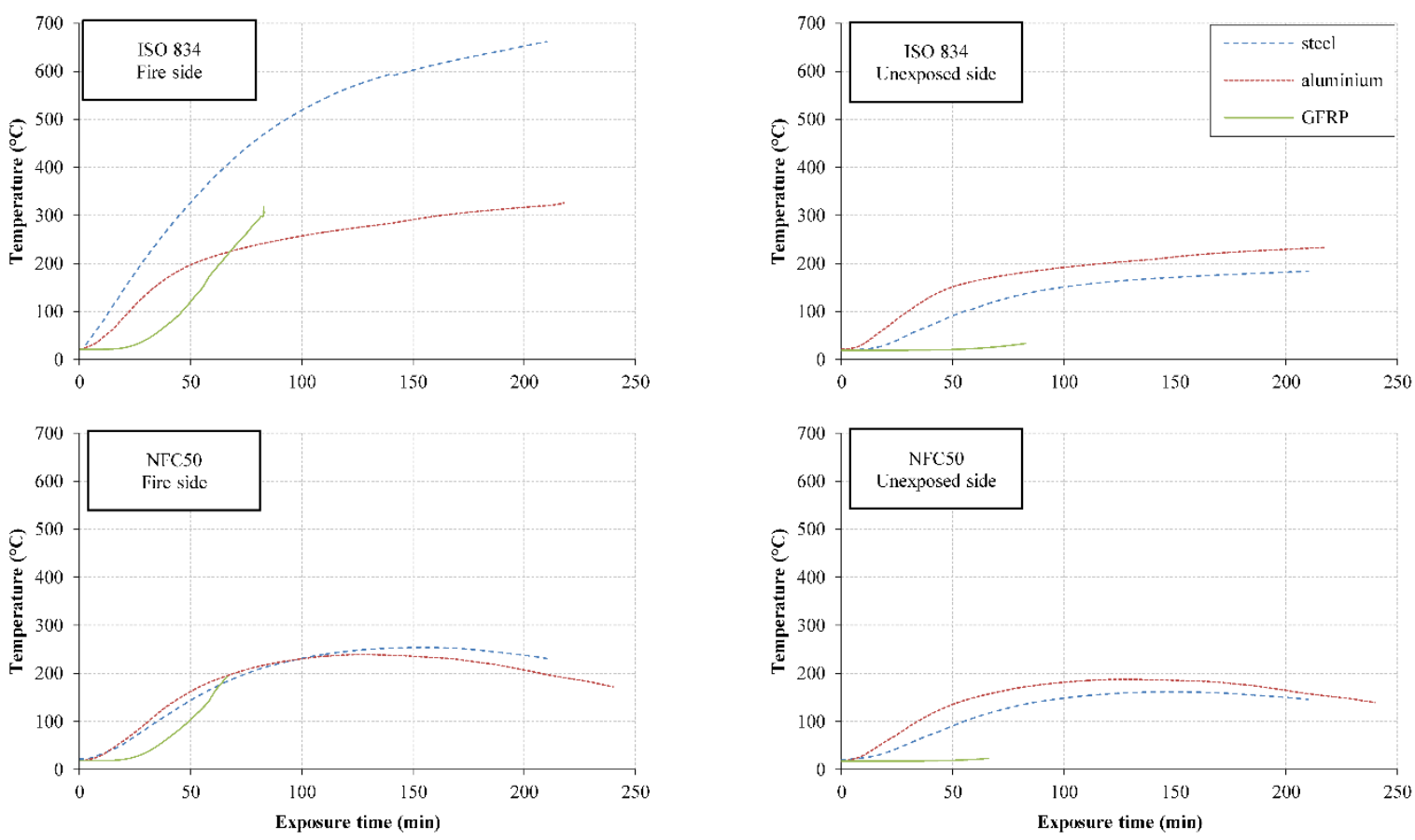

Figure 3 - Temperature recordings on exposed and unexposed sides of each structure type for both exposure curves. On the exposed side, thermocouples are located between insulation and panel.
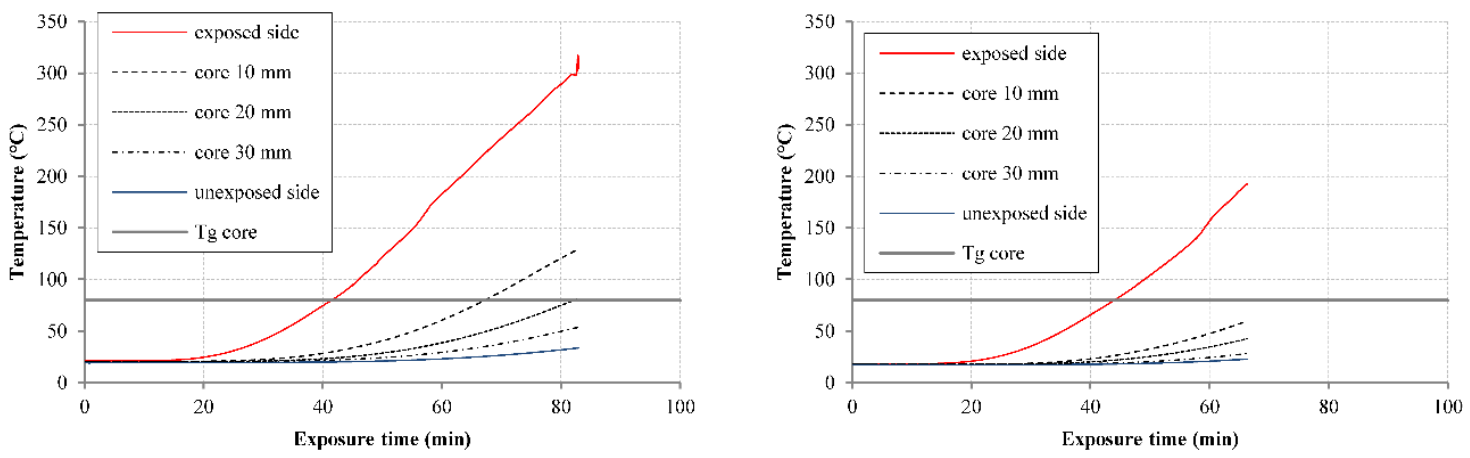

Figure 4 - Temperature recordings through the thickness of the FRP bulkheads including measurements in the core material 

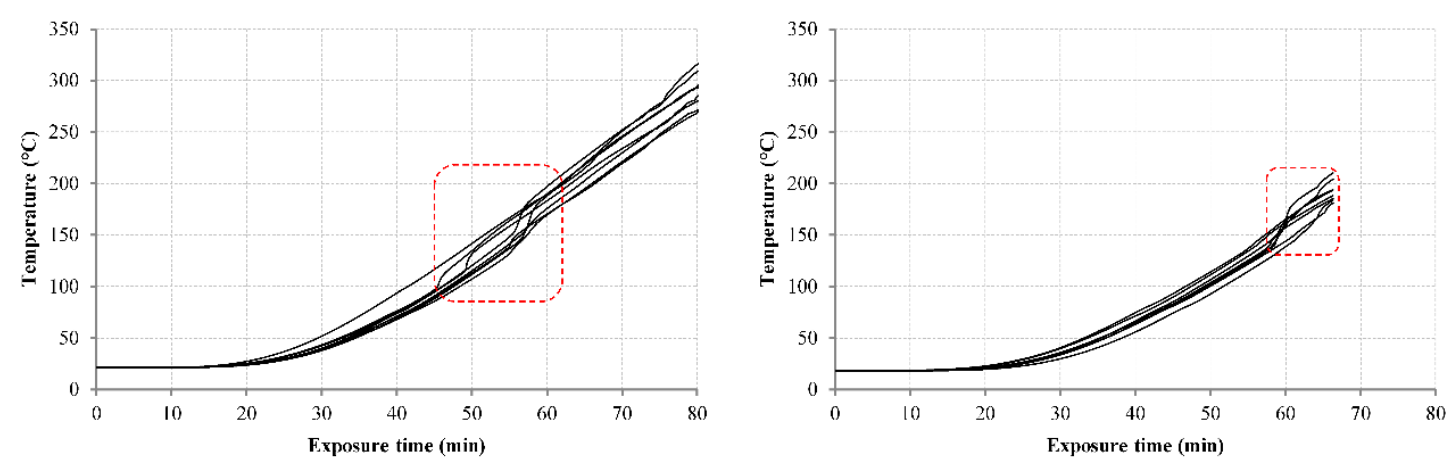

Figure 5 - Temperature recordings from individual thermocouples on the fire side facesheet of the FRP bulkhead tested with ISO 834 (left) and NFC50 (right) fire curves. The sudden temperature increase is highlighted in red.
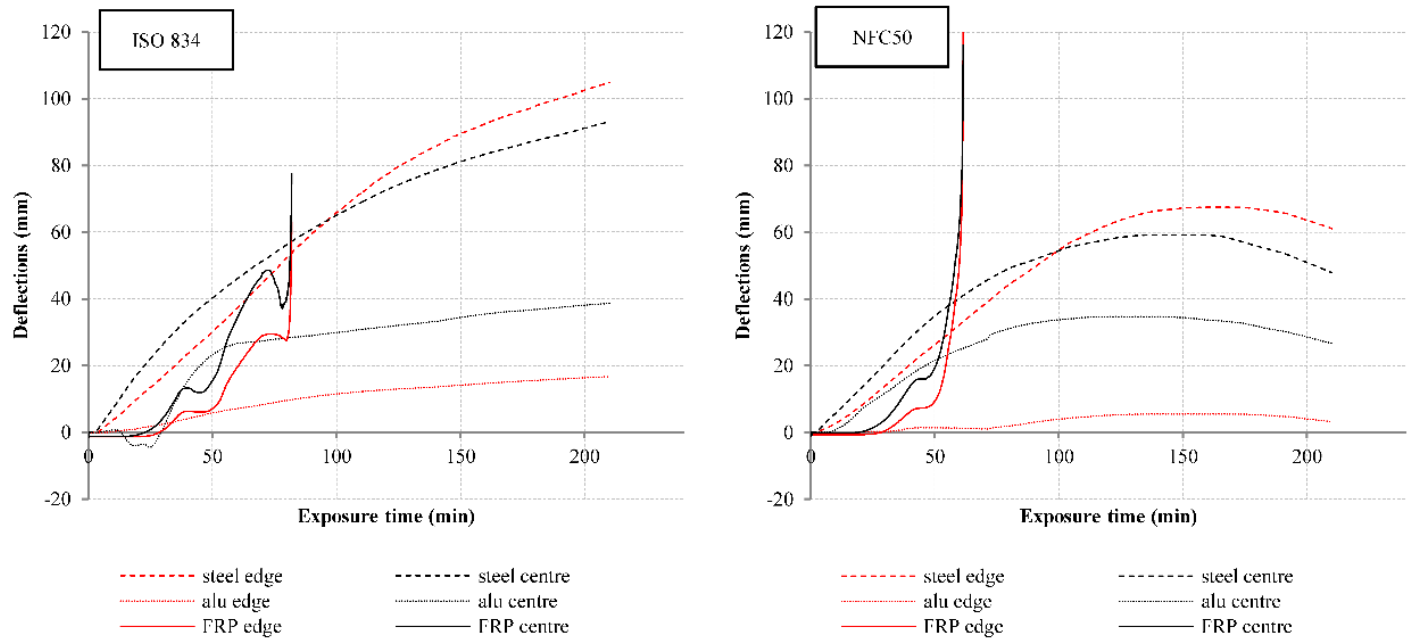

Figure 6 - Deflection measurements for each bulkhead type and both exposure curves 


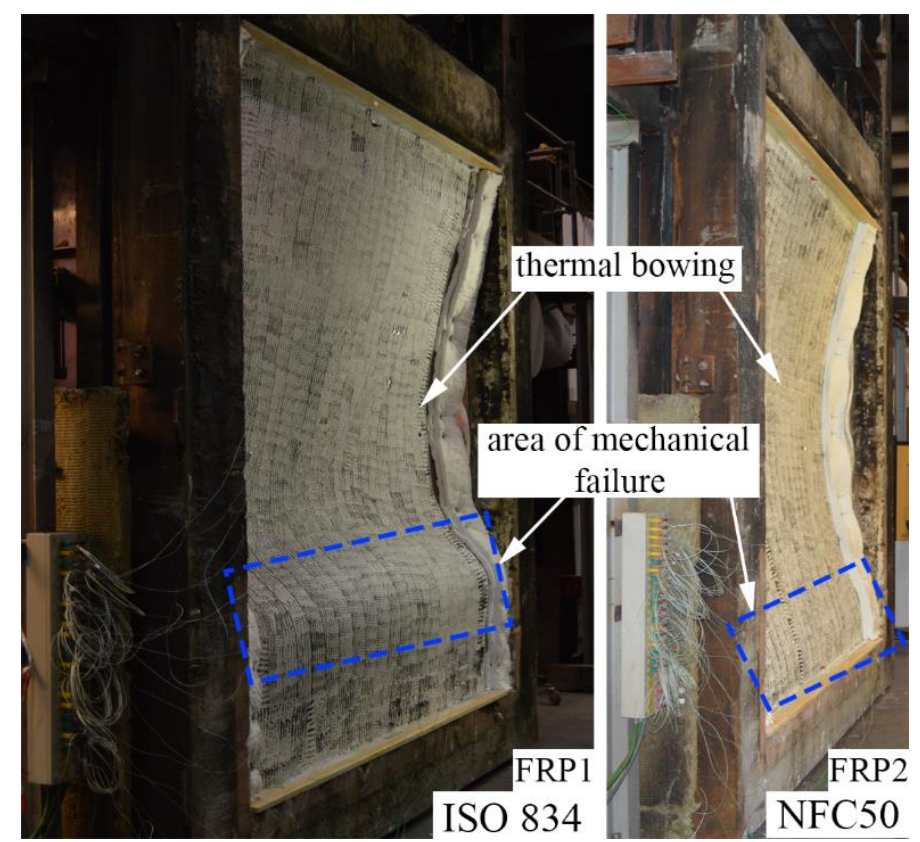

Figure 7 - Failure pattern of FRP bulkhead exposed to ISO 834 curve (left) and NFC50 curve (right)

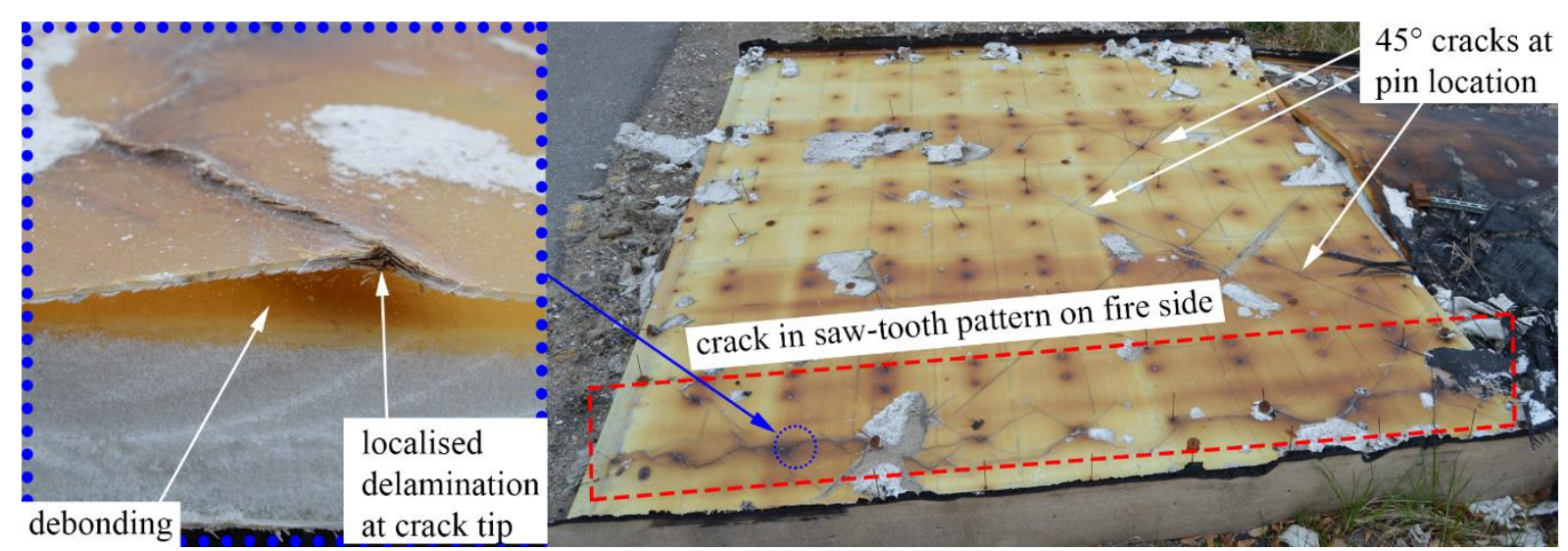

Figure 8 - FRP facesheet on the fire side for specimen FRP2. Face/core interaction was lost at failure location and delamination of FRP layers occurred at crack tip (a); crack visible on full bulkhead width in saw-tooth pattern (b). 


\section{LIST OF TABLES}

Table 1 - Overview of test specimens and test configurations.

\begin{tabular}{lccccccc}
\hline ID & Material & $\begin{array}{c}\text { Dimensions } \\
{[\mathbf{m m}]}\end{array}$ & $\begin{array}{c}\text { Insulation } \\
{[\mathbf{m m}]}\end{array}$ & $\begin{array}{c}\text { Total thickness } \\
{[\mathbf{m m}]}\end{array}$ & $\begin{array}{c}\text { Exposure } \\
\text { curve }\end{array}$ & $\begin{array}{c}\text { Load } \\
{[\mathbf{k N . m}} \\
\mathbf{1}]\end{array}$ & $\begin{array}{c}\text { Usage } \\
{[\%]}\end{array}$ \\
\hline S1 & \multirow{2}{*}{ Steel } & $\begin{array}{c}2930 \mathrm{x} \\
3120\end{array}$ & \multirow{2}{*}{75} & \multirow{2}{*}{131.5} & ISO 834 & 7 & 1.35 \\
S2 & \multirow{2}{*}{ NFCC50 } & 134 & 26 \\
\hline A1 & \multirow{2}{*}{ Aluminium } & $\begin{array}{c}2930 \mathrm{x} \\
3120\end{array}$ & \multirow{2}{*}{50} & \multirow{2}{*}{136} & ISO 834 & 7 & 2.85 \\
A2 & & & NFC50 & 61 & 50 \\
\hline FRP1 & \multirow{2}{*}{ FRP } & $\begin{array}{c}2930 \mathrm{x} \\
\text { FRP2 }\end{array}$ & \multirow{2}{*}{100} & \multirow{2}{*}{143} & ISO 834 & 7 & 19.5 \\
\hline
\end{tabular}

Table 2 - Loading conditions for specimens tested with natural fire curves NFC 50

\begin{tabular}{ll|ccc}
\cline { 3 - 5 } & & Steel & Aluminium & FRP \\
\hline Applied load & {$[\mathrm{tons}]$} & 40 & 18.3 & 5.4 \\
Linear load & {$\left[\mathrm{kN} \cdot \mathrm{m}^{-1}\right]$} & 134 & 61 & 18.1 \\
Load-bearing capacity & {$\left[\mathrm{kN} \cdot \mathrm{m}^{-1}\right]$} & 510 & 123 & 36 \\
Utilisation & {$[\%]$} & 26 & 50 & 50 \\
\hline
\end{tabular}

Table 3 - Overview of test results according to the FTP Code requirements and mechanical failure within $4 \mathrm{~h}$ of exposure. FTPC criteria have limited meaning for natural fire curves, as a natural fire will burn for more than $1 \mathrm{~h}$, whether hotter or cooler than the ISO 834 standard curve.

\begin{tabular}{lccc}
\hline \multicolumn{1}{c}{ ID } & Exposure curve & FTPC $(\mathbf{6 0}$ min $)$ & Mechanical failure before $4 \mathbf{h}$ of exposure \\
\hline S1 & ISO 834 & Pass & None \\
S2 & NFC50 & Pass & None \\
\hline A1 & ISO 834 & Fail $\left(+143^{\circ} \mathrm{C}\right)$ & None \\
A2 & NFC50 & Pass & None \\
\hline FRP1 & ISO 834 & Pass & $82 \mathrm{~min}$ \\
FRP2 & NFC50 & Pass & $61 \mathrm{~min}$ \\
\hline
\end{tabular}

